\title{
Technology-assisted communication in older persons in a residential care facility in South Africa
}

\author{
Jennifer Chipps and Mary Ann Jarvis
}

\begin{abstract}
Relocation to residential care facilities by older persons (6op) can decrease their social connectedness with their primary networks. The purpose of the study was to identify the use and acceptance of technology-assisted communication to increase social connectedness in older persons $(\mathrm{N}=103)$ in an urban residential care facility in South Africa. The research design was a non-experimental quantitative descriptive survey using self-administered questionnaires based on the Technology Acceptance Model. All residents were included in the study. Perceived Ease of Use, Perceived Usefulness and Attitude scales were calculated and the Behavioural Intention for technology use was measured. Participants with the highest Behavioural Intention were residents in their first year of relocation, younger participants (60-74 years), divorced participants and participants with higher educational qualifications. Perceived Ease of Use and Perceived Usefulness were low and were directly correlated. Perceived Ease of Use contributed significantly towards Attitudes concerning technology use. The overall Behavioural Intention for technology use was good (60/75) and the Technology Acceptance Model pathway was confirmed using Structural Equation Modelling. Video chat offered greatest appeal for future use.
\end{abstract}

\section{Introduction and background}

Globally life expectancy is increasing and this trend is set to continue in both developed and developing countries (Wang et al., 2013). Accompanying this trend is the rising rate of depression in older persons (6op), particularly where older persons are relocated to residential care (Drageset, Kirkevold and Espehaug, 2011; Nyqvist, Nygård and Jakobsson, 2012; Tiong et al., 2013). Depression rates internationally in residential care settings have been recorded between 16.9-49\% (Golden et al., 2009; Drageset et al., 2011; Luppa et al., 2012; Solhaug et al., 2012; Tiong et al., 2013), while a South African study has recorded rates of decreased mental well-being as high as $49.3 \%$ (Chipps and Jarvis, 2015). Although studies have varied in their agreement about older persons' social networks shrinking (van Kemenade, Roy and Bouchard, 2006; Cornwell and Waite, 2009; van Groenou, Hoogendijk and van Tilburg, 2013), in these settings the impact of this reduced social network on the older persons' social network and their mental wellbeing is most marked. 
Various technology-assisted communication strategies have been suggested for enhancing older persons' social contact, expanding and strengthening their social networks, increasing their social connectedness and alleviating depression and loneliness (White et al., 2002; Fokkema and Knipscheer, 2007; Cotton, Anderson and McCullough, 2013). These studies included Internet training and its use, with, for example, Fokkema and Knipscheer (2007) reporting that after two years of Internet use, significant reductions in the loneliness scores of older people were recorded (8.1 SD 2.4 to $6.7 ; \mathrm{p}=.05$ ). The study by Cotton et al., (2013) showed a significant 0.147-point decrease in loneliness for every 1point increase in frequency of going online.

However, most of the research on this emanates from developed countries, with studies mainly on Internet usage and video chat (Nahm, Resnick and Mills, 2003; Keating, Swindle and Foster, 2005; Fokkema and Knipscheer, 2007; Tsai et al., 2010). The mHealth Alliance, United Nations Foundation (Kwan, 2013) has recognized this gap in lowermiddle income countries in a white paper which emphasizes the strong relevance of harvesting the potential of mobile technologies to allow for the fullest benefit to be reaped by older persons' mental health.

There are a number of challenges for older persons in using technology-assisted communication, related to fear of technology and feelings of being overwhelmed by computer technology (Fokkema and Knipscheer, 2007; Tsai et al., 2010; Chen and Chan, 2014). Studies have shown difficulties in winning the cooperation of older persons to use these technologies. In a Taiwanese quasi-experimental study examining the utility of videoconferencing as a social support tool, a $71.4 \%(\mathrm{n}=154)$ rejection rate was registered (Tsai et al., 2010).

Factors contributing to the successful use of technology in these studies included significant predictors of usage, inclusive of attitudes, perceived usefulness of technology, good health, and being male (Nayak, Priest and White, 2010). A key issue in technology-related projects in older people is the successful acceptance of technology as set out by the Technology Acceptance Model (TAM) (Davis, 1989). The model has the premise that user acceptance requires a precondition of perceptions of ease of use of technology and usefulness of technology (Davis, 1989). Perceptions of the ease of use and usefulness of technology may also influence attitudes of importance to expend effort in the selected technology (Holden and Karsh, 2010), which in turn will impact on the behavioural intention, the motivator, to use the technology (Davis, 1989; Lu et al., 2003; Holden and Karsh, 2010). Behavioural intention predicts the actual use of technology (Turner et al., 2010). Perceived usefulness and perceived ease of use of technology may be influenced by cultural and demographic factors, and physical limitations such as deficits in dexterity, sight and hearing (Renaud and van Biljon, 2008).

Despite the TAM not being designed for the prediction of e-health use, it has been adopted in various settings (Holden and Karsh, 2010). There has been some criticism of the TAM in that it fails to recognize facilitating conditions and social influence as reflected in the 
Unified Theory of Acceptance and Use of Technology (UTAUT) (Holden and Karsh, 2010). Chen and Chan (2014), in an attempt to understand gerontology acceptance, utilized the TAM and the UTAUT to create the Senior Technology Acceptance Model (STAM); however, in so doing, as with other variances of the TAM (Turner et al., 2010), Behavioural Intention was not recognized, yet Attitudes were retained.

The TAM (Davis, 1989) was used to evaluate, from a technology acceptance perspective, the use and acceptance of technology-assisted communication by older persons living in Durban, South Africa.

\section{Purpose of study}

The objectives of the study were to determine access of older persons (6op) living in a residential setting in South Africa to technology-assisted communication devices for social connectedness, the acceptance of technology using the TAM model and the impact of demographic factors on the acceptance of technology in older people. This study was conducted to inform the planning of an initiative to reduce loneliness in older people using technology-assisted communication devices.

\section{Methodology}

The residential care facility was one of 15 non-governmental residential facilities offering degrees of care for older persons (6op years) in Durban, South Africa. Sampling was done in two stages.

Firstly, the independent living section in one of the 15 facilities was selected, based on the large number of independent residents and the availability of resources to support a future intervention. Secondly, all-inclusive sampling was carried out with all $(\mathrm{N}=103)$ residents being eligible for inclusion in the study.

The authors adapted a researcher-administered questionnaire (Appendix A) from the Technology Acceptance Model (TAM) (Figure 2) (Davis, 1989; Lu, Yu, Liu and Yao, 2003). The model is based on the Theory of Reasoned Action, expanded to the Theory of Planned Behaviour evolving through the stages of subjective perception as a primary determinant and shaped by external variables, attitudes, behavioural intentions to use technology and ultimately actual use (Davis, 1989; Lu, Yu, Liu and Yao, 2003).

The questionnaire consisted of six sections, measuring demographics, current access to technology-assisted communication devices, and the four TAM constructs or sub-scales, namely: Perceived Ease of Use, Perceived Usefulness, Attitudes and Behavioural Intention. The subscales (Perceived Ease of Use, Perceived Usefulness), each consisted of 16 questions enquiring about the ease of use and usefulness of a range of mobile phone and computer functions such as the receipt and sending of calls, text and instant messaging, playing games, video-chat, e-mail, social media and use of Internet. Perceived Ease of Use and Usefulness items were measured on 5 -point Likert scales ( $0=$ don't use; $1=$ very difficult $/$ not useful at all, $2=$ difficult/somewhat useful, $3=$ easy/useful, $4=$ easy to 
use/very useful) in keeping with the TAM hypothesis that the primary determinant of a person's willingness to embrace technology is the perception of the device's usefulness and ease of use (Davis, 1989). Attitude and Behavioural Intention were measured using 11 yes/no responses, focusing on attitude and intention towards usage of communication technology for contact with family or friends. A pre-test was conducted with three (3) residents who were asked to assess the ease of completing each question from 'easy' to with difficulty'. Only minor language changes were made to the questionnaire after pretesting and data from the pre-tests were excluded. Content validity was addressed through the use of the TAM framework.

The questionnaire had good internal consistency with Cronbach's alpha of .854 for PEU scale and .862 for PU scale. To ensure that the participants were familiar with the technology-assisted devices in the questionnaire, small groups of participants (20 per session) were exposed to an orientation session which involved demonstrations of a variety of technology-assisted forms of communication. Data was then collected in September/October 2013 over 8 days with two orientation sessions per day.

To test the influence of age on the model, age was recoded into two groups, younger participants (60-75 years) and older participants (76p years). Perceived Ease of Use and Perceived Usefulness scores were calculated out of a possible 64, with individual items scored out of 4 and separate sub-scores for mobile phones and computers. An Attitude score was calculated out of 7. Behavioural Intention was rated as 'Yes' or 'No' based on current use and future intended use. Descriptive statistics, Chi-square Tests $\left(\mathrm{X}^{2}\right)$ and MannWhitney (U) and Kruskal-Wallis (K) non-parametric tests were calculated to test the association between the variables and the different components of the TAM model. Though the number of subjects was low, but adequate for linear regression (Gefen, Straub and Boudreau, 2000), a simple structural model was constructed using AMOS v23 to test the regression pathways of selected TAM variables on Behavioural Intention as an indication of use. The significance level was set at $\mathrm{p}=<.05$.

Written permission for this study was received from the facility and ethical approval was obtained from the Human Social Science Research Ethics Committee of the University of KwaZulu-Natal.

\section{Results}

A total of 75 (73\%) residents completed the questionnaire. The remaining 28 residents were either not present in the residence at the time of data collection or declined to participate. The average age of the participants was 78.2 years (SD 8.2) with the predominant age group being the older participants $(76 \mathrm{p})(\mathrm{n}=44,58.7 \%)$. Almost all participants ( $\mathrm{n}=68,90.7 \%)$ were English-speaking and just over half $(\mathrm{n}=39,52.0 \%)$ had completed 12 years of schooling. In terms of marital status, the largest proportion of participants was widowed. A higher proportion of older participants $(n=31,70.5 \%)$ than younger participants $(\mathrm{n}=14,45.2 \%, \mathrm{p}=.004)$ were widowed (Table 1$)$. 
Access and use of technology

Access to technology as both computer and mobile phones was assessed to identify both availability and current use. Computer usage was low among the participants with only six (8.0\%) owning a computer and only four (5.3\%) owning computers with Internet connectivity.

Table I. Demographics and access to technology.

\begin{tabular}{|c|c|c|c|c|c|}
\hline & & $\begin{array}{c}\text { Total } \\
\mathrm{n}=75\end{array}$ & $\begin{array}{c}60-75 \text { years } \\
\text { (young old) } \\
n=31\end{array}$ & $\begin{array}{c}76-100 \text { years } \\
\text { (older old) } \\
n=44\end{array}$ & Test $p$-value \\
\hline \multirow[t]{3}{*}{ Gender n(\%) } & Male & 17 (22.7\%) & $8(25.8 \%)$ & $9(20.5 \%)$ & $X^{2}=0.3 p=.586$ \\
\hline & Female & $58(77.3 \%)$ & $23(74.2 \%)$ & 35 (79.5\%) & \\
\hline & White & $58(77.3 \%)$ & $25(80.6 \%)$ & $33(75 \%)$ & \\
\hline \multirow[t]{2}{*}{ Language n(\%) } & English & $68(90.7 \%)$ & $29(93.5 \%)$ & $39(88.6 \%)$ & $X^{2}=0.6 p=.753$ \\
\hline & Other & 7 (9.3\%) & $2(6.5 \%)$ & $5(11.4 \%)$ & \\
\hline \multirow[t]{3}{*}{ Marital Status (n)\% } & Never married & II (|4.7\%) & $3(9.7 \%)$ & $8(18.2 \%)$ & $X^{2}=10.7 p=.004^{*}$ \\
\hline & Divorced & $19(22.7 \%)$ & $14(45.2 \%)$ & 5 (11.4\%) & \\
\hline & Widowed & $45(60 \%)$ & 14 (45.2\%) & 31 (70.5\%) & \\
\hline \multirow[t]{3}{*}{ Education Level n(\%) } & Primary & II (I4.7\%) & $5(16.1 \%)$ & $6(13.6 \%)$ & $X^{2}=0.1 p=.941$ \\
\hline & School leaving & $46(61.3 \%)$ & $19(61.3 \%)$ & 27 (6I.4\%) & \\
\hline & tertiary & $18(24.0 \%)$ & $7(22.6 \%)$ & II (25.0\%) & \\
\hline \multirow[t]{3}{*}{ Time in residence $\mathrm{n}(\%)$} & $<$ Iyear & $25(33.3 \%)$ & $13(41.9 \%)$ & $12(27.3 \%)$ & $X^{2}=2.0 p=.372$ \\
\hline & $1-5$ years & $34(45.3 \%)$ & 13 (4I.9\%) & $21(47.7 \%)$ & \\
\hline & $5+$ years & $16(21.3 \%)$ & $5(16.1 \%)$ & II (25.0\%) & \\
\hline \multirow{3}{*}{$\begin{array}{l}\text { Access to Technology } \\
\mathrm{n}(\%)\end{array}$} & Landline in room & $39(52 \%)$ & $13(41.9 \%)$ & $26(59.1 \%)$ & $X^{2}=2.1 p=.143$ \\
\hline & Own mobile phone & 57 (76\%) & $25(80.6 \%)$ & $32(72.7 \%)$ & $X^{2}=0.6 p=.429$ \\
\hline & Internet access & $4(5.3 \%)$ & $2(6.5 \%)$ & $2(4.5 \%)$ & $X^{2}=1.5 p=.221$ \\
\hline
\end{tabular}

Demographic variables of gender, language, marital status, educational level and time in residence were tested for differences in age groups and access to technology using chi-squared $\left(X^{2}\right)$; *p-value of significance set at $<.05$

All but one participant ( $\mathrm{n}=74,98.7 \%)$ had access to a device that allowed for communication with their primary network, the most prominent being ownership of or access to a mobile phone $(n=57,76 \%)$, followed by a landline $(n=39,52.0 \%)$ (Table 1$)$. There was no statistically significant difference in ownership of mobile phones between the younger $(n=25,80.6 \%)$ and the older participants $(n=32,72.7 \%)\left(X^{2}=0.6 p=.429\right)$.

All participants with mobile phones used them to receive or make calls, with two-thirds having carried out these activities for over a year. Eighteen participants (24.0\%) reported having smart phones and of these 11 were owned by older participants (76p years). Only six participants (17.6\%) reported that they used mobile phones to send text messages more than once a week. The six participants (8.0\%) who owned a computer used them for Internet searches (4), receiving and sending emails (4), social media (4) and video chat (3). Usage of texting $(\mathrm{K}=6.9, \mathrm{p}=.032)$ was highest among participants in the first year of living in the residence, with consecutive years of residence showing a decline in usage.

Mobile phones were used by both younger and older participants more than once a week to receive calls ( $n=46,76.7 \%)$, but more by the older participants $(n=25,73.5 \%)$. There were significant differences in the marital groups in sending text messages usages $(K=9.6$, 
$\mathrm{p}=$.002), with usage among the divorced participants being the highest. A further difference in text message usage was found in participants with different educational levels. Frequency of receiving $(\mathrm{K}=11.7, \mathrm{p}=.008)$ and sending $(\mathrm{K}=8.5, \mathrm{p}=.036)$ text messages was highest among participants with tertiary level education.

\section{Perceived Ease of Use (PEU)}

Perceived Ease of Use (PEU) was measured for the multiple functions of both mobile phones and computers (Table 2).

The overall Perceived Ease of Use scores out of a possible 64 were low (10.9 SD 9.3; median 9.0, range o to 42). Perceived Ease of Use scores for mobile phones were higher than for computers (1.0 SD 0.8 vs 0.2 SD 0.7) with the highest average ratings being recorded for making and receiving calls and text messages (Table 2). Receiving calls was unsurprisingly rated as the easiest activity ( $\mathrm{n}=58,77 \cdot 3 \%)$.

There were significant associations between average Perceived Ease of Use scores for mobile phone use, but not for computer usage or for age groups (Table 2).

Table 2. Perceived Ease of Use of mobile phone and computer functions.

\begin{tabular}{|c|c|c|c|c|c|}
\hline Device & TOTAL & $\begin{array}{c}\text { 60-75 years (younger } \\
\text { participants) } \\
n=31\end{array}$ & $\begin{array}{c}\text { 76- } 100 \text { years (older } \\
\text { participants) } \\
n=44\end{array}$ & Test & $\mathrm{p}$-value \\
\hline Mobile phone & $\mathrm{I} .0(0.8)$ & $1.2(0.9)$ & $0.8(0.7)$ & $U=2.1$ & $\mathrm{p}=.040 *$ \\
\hline Making mobile phone calls & $2.7(1.6)$ & $2.8(1.5)$ & $2.6(1.6)$ & $U=0.5$ & $p=.636$ \\
\hline Receiving mobile phone calls & $2.8(1.5)$ & $2.9(1.4)$ & $2.8(1.6)$ & $U=0.3$ & $\mathrm{p}=.799$ \\
\hline Sending text messages & $1.5(1.8)$ & $2.2(1.8)$ & I.I (I.6) & $U=2.9$ & $\mathrm{p}=.005^{*}$ \\
\hline Receiving text messages & $\mathrm{I} .8(1.7)$ & $2.3(1.8)$ & $\mathrm{I} .4(\mathrm{I} .7)$ & $U=2.3$ & $\mathrm{p}=.019 *$ \\
\hline Instant messaging & $0.3(1)$ & $0.5(1.3)$ & $0.2(0.7)$ & $U=1.0$ & $\mathrm{p}=.337$ \\
\hline Mobile phone video chat & $0.1(0.6)$ & $0.1(0.7)$ & $0.1(0.5)$ & $U=0.3$ & $\mathrm{p}=.787$ \\
\hline Mobile phone email & $0.1(0.5)$ & $0.1(0.7)$ & $0(0.3)$ & $U=0.3$ & $\mathrm{P}=.787$ \\
\hline Mobile phone social media & $0.1(0.6)$ & $0.1(0.7)$ & $0.1(0.5)$ & $U=0.3$ & $\mathrm{p}=.787$ \\
\hline Mobile phone Internet & $0.1(0.7)$ & $0.1(0.7)$ & $0.1(0.6)$ & $U=0.3$ & $\mathrm{p}=.800$ \\
\hline Mobile phone games & $0.2(0.8)$ & $0.5(1.2)$ & $0(0)$ & $U=2.4$ & $\mathrm{p}=.015^{*}$ \\
\hline Computer & $0.2(0.7)$ & $0.3(1)$ & $0.1(0.5)$ & $U=0.9$ & $\mathrm{p}=.357$ \\
\hline Computer receiving emails & $0.2(0.9)$ & $0.3(1)$ & $0.2(0.7)$ & $U=0.9$ & $\mathrm{p}=.391$ \\
\hline Computer sending emails & $0.2(0.9)$ & $0.3(1)$ & $0.2(0.7)$ & $U=0.9$ & $\mathrm{p}=.391$ \\
\hline Computer video chat & $0.2(0.7)$ & $0.3(0.9)$ & $0.1(0.5)$ & $U=1.4$ & $p=.163$ \\
\hline Computer Internet & $0.2(0.8)$ & $0.3(1)$ & $0.1(0.5)$ & $U=0.9$ & $\mathrm{p}=.357$ \\
\hline Computer games & $0.1(0.7)$ & $0.2(0.9)$ & $0.1(0.5)$ & $U=0.9$ & $\mathrm{p}=.358$ \\
\hline Computer social media & $0.2(0.7)$ & $0.3(1)$ & $0.1(0.5)$ & $U=1.4$ & $p=.159$ \\
\hline Perceived Ease of Use (PEU) Score/64 & $10.9(9.3)$ & $13.5(10.4)$ & $9(8.1)$ & $\mathrm{U}=2.2$ & $\mathrm{p}=.029 *$ \\
\hline
\end{tabular}

Perceived Ease of Use of mobile phones and computers for younger and older participants was tested for differences using the nonparametric Mann-Whitney $U$ test.; *p-value of significance set at $<.05$

Age $(\mathrm{U}=2.1, \mathrm{p}=.040)$, level of education $(\mathrm{K}=8.2 ; \mathrm{p}=.014)$ and time in residence $(\mathrm{K}=7.0 ; \mathrm{p}$ $=.031$ ) were all significant contributors towards the Perceived Ease of Use score for mobile phones. There were significant differences in Perceived Ease of Use scores between the younger participants and the older participants in terms of receiving text messages $(U=$ 
2.3, $\mathrm{p}=.019)$, sending text messages $(\mathrm{U}=2.8, \mathrm{p}=.005)$ and playing games $(\mathrm{U}=2.4$, $\mathrm{p}=.015)$.

\section{Perceived Usefulness (PU)}

Perceived Usefulness (PU) was measured for all the multiple functions of both mobile phones and computers (Table 3). The total Perceived Usefulness scores were also higher (10.9 SD 9.8; median 8.0, range o to 45.0) for mobile phones than for computers (Table 3).

There were statistically significant differences in Perceived Usefulness for age groups $(\mathrm{U}=2.7, \mathrm{p}=.006)$ (Table 3$)$, levels of education $(\mathrm{K}=8.5, \mathrm{p}=.014)$, time in residence $(\mathrm{K}$ $=7.0, \mathrm{p}=.029)$ and marital status $(\mathrm{K}=7.7, \mathrm{p}=.021)$. Perceived Usefulness was highest among participants who were younger, tertiary educated, divorced, and newest in the residence. The highest rated activity amongst the participants for Perceived Usefulness was for receiving calls $(53,71.7 \%)$.

There was a strong correlation between Perceived Ease of Use and Perceived Usefulness scores $(\mathrm{r}=.969, \mathrm{n}=75, \mathrm{p}<.001)$ with high levels of Perceived Ease of Use associated with high levels of Perceived Usefulness and $93.8 \%$ of the variance in Perceived Usefulness being explained by the Perceived Ease of Use score.

\section{Attitudes}

Overall the participants had positive attitudes towards the use of technology, with agreement on the attitude statements ranging from 18 (40.9\%) in older participants for whether technology-assisted communication could be used to contact people to $23(74.2 \%)$ in the younger participants for liking technology-assisted communication and being happy to use technology-assisted communication (Table 4). There were no significant differences for age group, gender and education. There was a significant difference in marital status (K $=8.7, \mathrm{p}=.034$ ) with divorced and widowed participants and participants in residence for less than 5 years having higher agreements on the positive attitudes $(K=9.3, p=.010)$. 
Table 3. Perceived Usefulness of mobile phone and computer functions.

\begin{tabular}{|c|c|c|c|c|c|}
\hline Technology device & TOTAL & $\begin{array}{c}\text { 60-75 years (young old) } \\
n=31\end{array}$ & $\begin{array}{c}\text { 76- } 100 \text { years (older old) } \\
n=44\end{array}$ & Test & p-value \\
\hline Mobile phone & I.I (0.8) & I.4 (0.9) & $0.9(0.7)$ & $U=2.7$ & $\mathrm{p}=.006^{*}$ \\
\hline Making mobile phone calls & $2.7(1.6)$ & $3(1.5)$ & $2.4(1.6)$ & $\mathrm{U}=\mathrm{I} .7$ & $\mathrm{p}=.08 \mathrm{I}$ \\
\hline Receiving mobile phone calls & $2.8(1.6)$ & $3.1(1.5)$ & $2.6(1.6)$ & $U=1.6$ & $p=.115$ \\
\hline Sending text messages & $\mathrm{I} .5(1.8)$ & $2.3(1.9)$ & I (I.6) & $U=3.2$ & $\mathrm{p}=.00 \mathrm{I}^{*}$ \\
\hline Receiving text messages & $1.8(1.8)$ & $2.5(1.9)$ & $\mathrm{I} .4(1.7)$ & $U=2.7$ & $\mathrm{p}=.007^{*}$ \\
\hline Instant messaging & $0.3(1)$ & $0.6(1.4)$ & $0.1(0.7)$ & $U=I .7$ & $p=.086$ \\
\hline Mobile phone video chat & $0.1(0.3)$ & $0.1(0.4)$ & $0(0.3)$ & $U=0.3$ & $\mathrm{p}=.802$ \\
\hline Mobile phone email & $0.1(0.5)$ & $0.1(0.7)$ & $0(0.3)$ & $U=0.3$ & $\mathrm{p}=.787$ \\
\hline Mobile phone social media & $0.1(0.6)$ & $0.1(0.7)$ & $0.1(0.5)$ & $U=0.3$ & $\mathrm{p}=.787$ \\
\hline Mobile phone Internet & $0.1(0.7)$ & $0.1(0.7)$ & $0.2(0.7)$ & $U=0.3$ & $p=.788$ \\
\hline Mobile phone games & $0.1(0.5)$ & $0.2(0.8)$ & $0(0)$ & $U=2.4$ & $\mathrm{p}=.015^{*}$ \\
\hline Computer & $0.2(0.8)$ & $0.3(1.1)$ & $0.1(0.6)$ & $U=0.9$ & $p=.357$ \\
\hline Computer receiving emails & $0.3(1)$ & $0.4(1.1)$ & $0.2(0.8)$ & $U=0.9$ & $\mathrm{p}=.397$ \\
\hline Computer sending emails & $0.3(1)$ & $0.4(I .1)$ & $0.2(0.8)$ & $U=0.9$ & $\mathrm{p}=.397$ \\
\hline Computer video chat & $0.2(0.8)$ & $0.3(1)$ & $0.1(0.5)$ & $U=I .4$ & $p=.159$ \\
\hline Computer Internet & $0.2(0.9)$ & $0.4(I . I)$ & $0.1(0.7)$ & $U=0.9$ & $\mathrm{p}=.370$ \\
\hline Computer games & $0.1(0.7)$ & $0.3(1)$ & $0.1(0.5)$ & $U=0.9$ & $\mathrm{p}=.350$ \\
\hline Computer social media & $0.2(0.8)$ & $0.4(1.1)$ & $0.1(0.5)$ & $U=I .4$ & $p=.155$ \\
\hline Perceived Usefulness Score/64 & $10.9(9.9)$ & $14.2(10.8)$ & $8.5(8.5)$ & $U=2.7$ & $\mathrm{p}=.006 *$ \\
\hline
\end{tabular}

Perceived Usefulness of mobile phones and computers for younger and older participants was tested for differences using the nonparametric Mann-Whitney $U$ test.; ${ }^{*} \mathrm{p}$-value of significance set at $<.05$

In examining the various technology and programs available, video chat offered the greatest overall appeal $(29,38.7 \%)$. In the younger participants $16(51.6 \%)$ preferred video chat as compared to email for older participants $(19,43.2 \%)$.

Hierarchical multiple regression was used to assess the ability of TAM model measures (PEU and PU) to predict Attitudes, after controlling for the influence of age and time in residence. Preliminary analyses were conducted to ensure no violation of the assumptions of normality, linearity, multi-collinearity and homo-scedasticity. Due to the high correlation between PEU and PU, PU was dropped from analysis. Age and time in residence were entered at Step 1, explaining 8.6\% of the variance in Perceived Ease of Use. After entry of the Perceived Ease of Use measure at Step 2 the total variance explained by the model as a whole was $37.3 \%, \mathrm{~F}(3,74)=14.1, \mathrm{p}<.001$. The control measures explained an additional 26.2\% of the variance in Perceived Ease of Use, after controlling for age and time in residence. In the final model, the Perceived Ease of Use measure recorded a higher b value $(\mathrm{b}=.548, \mathrm{p}<.001)$ than the time in residence measure $(\mathrm{b}=-.234, \mathrm{p}<.001)$. In examining the contribution of Perceived Ease of Use $(b=.377)$ and Perceived Usefulness $(b=.233)$ scores to Attitudes, both scores contributed with $37.7 \%$ and $23.3 \%$ of the variance respectively.

\section{Behavioural Intention}

Behavioural Intention included both current use and intention to use technology. Of the 75 participants, $65(86.7 \%)$ indicated an intention to use and 10 (13.3\%) did not. 
There was no difference in Behavioural Intention in terms of demographics. In analysing the association between Behavioural Intention and key predictors of use, there was a significant association with Attitude $(\mathrm{U}=3.1, \mathrm{p}=.002)$, Perceived Ease of Use (U $=4.7, \mathrm{p}<.001)$, Perceived Ease of Use (Mobile phone) $(\mathrm{U}=4.7, \mathrm{p}<.001)$, Perceived Usefulness ( $\mathrm{U}=4.7, \mathrm{p}<.001)$, Perceived Usefulness (Mobile phone) $(\mathrm{U}=4.7, \mathrm{p}<.001$ ) and time in residence $(\mathrm{U}=2.1, \mathrm{p}=038)$. Structured Equation Modelling was performed to assess the impact of the above variables on the prediction of Behavioural Intention (Figure 2).

Table 4. Attitudes towards use of technology-assisted communication.

\begin{tabular}{|c|c|c|c|c|c|}
\hline Attitude & TOTAL & $\begin{array}{c}60-75 \text { years } \\
\text { (young old) } \\
n=31\end{array}$ & $\begin{array}{c}76-100 \text { years } \\
\text { (older old) } \\
n=44\end{array}$ & Test & p-value \\
\hline TAC can be used to contact people & $35(46.7 \%)$ & 17 (54.8\%) & $18(40.9 \%)$ & $X^{2}=1.4$ & $p=.234$ \\
\hline TAC will improve contact with people & $48(64 \%)$ & $21(67.7 \%)$ & $27(61.4 \%)$ & $X^{2}=0.3$ & $p=.571$ \\
\hline $\begin{array}{l}\text { TAC will provide greater control of } \\
\text { contacts }\end{array}$ & $47(62.7 \%)$ & $20(64.5 \%)$ & $27(61.4 \%)$ & $X^{2}=0.1$ & $p=.781$ \\
\hline Easy to learn new TAC & $39(52 \%)$ & 17 (54.8\%) & $22(50 \%)$ & $X^{2}=0.2$ & $p=.680$ \\
\hline Positive attitude to TAC & $46(61.3 \%)$ & $19(61.3 \%)$ & $27(61.4 \%)$ & $X^{2}=0.0$ & $p=.995$ \\
\hline Like idea of contact using TAC & $54(72 \%)$ & $23(74.2 \%)$ & $31(70.5 \%)$ & $X^{2}=0.2$ & $p=.722$ \\
\hline Happy to use TAC & $54(72 \%)$ & $23(74.2 \%)$ & $31(70.5 \%)$ & $X^{2}=0.2$ & $p=.722$ \\
\hline Attitude Score /7 & 4.3 (SD 2.7) & $4.5(S D 2.8)$ & 4.2 (SD 2.6) & $\mathbf{U}=0.3$ & $p=.446$ \\
\hline
\end{tabular}

Differences in Attitudes of the younger and older participants towards the use of technology-assisted communication was tested using chi-square; *p-value of significance set at $<.05$

The structural model was statistically significant, $\mathrm{X}^{2}(5, \mathrm{~N}=75)=16.4, \mathrm{p}=<.006$, indicating that the model was able to distinguish between respondents with a positive and a negative Behavioural Intention. Age had a significant negative path loading on Perceived Ease of Use $(b=.-.279, p<.012)$, but time in residence did not. Perceived Ease of Use had a significant path loading on Attitudes $(\mathrm{b}=.563, \mathrm{p}<.001)$ and explained $39 \%$ of the variance in attitudes. Attitudes had a significant path loading on Behavioural Intention $(b=.385, p$ $<$.o01), explaining $15 \%$ of the variance in intention.

\section{Discussion}

The possibilities to increase social connectedness and reduce levels of social loneliness are high, with $98 \%$ of the participants having access to some device enabling communication with persons outside of the facility. However, despite the fact that the participants owned or had good access to mobile phones and used mobile phones for phoning and to some extent text messages, the Perceived Ease of Use and Perceived Usefulness of technology-assisted communication was low. Conci, Pianesi, and Zancanaro (2009) identified that older persons tend to stay at the point of early technology usage in their manipulation of the mobile phone. This can be of concern in the face of the loneliness that older persons may experience in residential care facilities (Drageset, et al., 2011), but reprieve is offered through the process of familiarization (Renaud and van Biljon, 2008) and in the presence of 
facilitating conditions such as technical and social support (Conci et al., 2009; Chen and Chan, 2014).

Mobile phones were owned and used more often than computers. Computer ownership and access to the Internet in South Africa is increasing (Stats SA 2014), but only 5.3\% of participants owned computers. Computers were mostly used to access the Internet and to receive and send emails, both functions being perceived as easy and useful. In contrast, all participants used their mobile phones to make and receive calls. However, the older participants used their mobile phones predominantly to receive calls. The receiving of calls was considered to be the easiest use of the mobile phone as well as its most advantageous function. The older participants found sending and receiving text messages both difficult and less useful, and did not report playing games on their mobile phones. This was echoed by Renaud and van Biljon (2008). Generally, smartphone features such as the Internet or video chat were seldom used, which aligns with the observation that mobile phone features are not used to their full capacity in older persons (Lee, 2007) and the primary reason for adopting a mobile phone is often linked to safety reasons (Conci et al., 2009).

A review of studies using the TAM model found that external variables are important in explaining contextual specific information that is essential in the prediction of behavioral intention (Strudwick, 2015). Participant groups with positive Behavioural Intention to use technology were younger participants (60 -75 years), divorced, of higher educational level, or in the first year of residence. The overall scores for Perceived Ease of Use and Perceived Usefulness were very low, but for mobile phones were highest in the first year in residence and decreased with longer stay. 


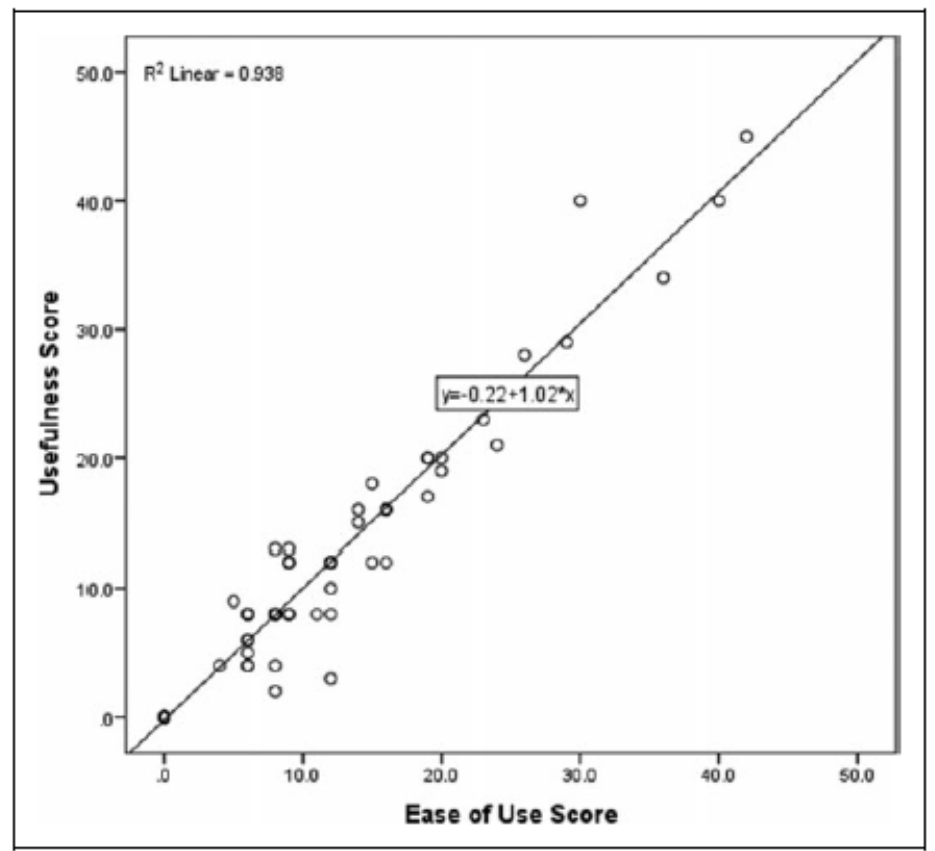

Figure I. Correlation between PEU and PU scores in residents.

The study confirmed the TAM model and found that the external variable of age significantly contributed to Perceived Ease of Use, which contributed to positive Attitudes. Attitudes significantly contributed to Behavioural Intention (Figure 1). Similar to other studies, age negatively influences Perceived Ease of Use with a decline in scores with increasing age. This is referred to as the 'digital divide' (Koivisto and Hamari, 2014). The digital divide needs be considered in the planning of the implementation of an econnectedness strategy, particularly in light of the presence of Intention to use the technologically assisted communication. Higher education level increases the likelihood of using technology (Chen and Chan, 2014). The South African residential care context offers the usual digital challenges, but in addition faces disparities in education and income (Pillay, Roberts, and Rule, 2006). This is given evidence in the earlier discussion on differences found in education and Behavioural intention. In addition, South Africa's Networked Readiness Index (NRI) (measure of the drivers of the ICT revolution, such as ICT readiness) has dropped from 70th out of 143 countries in 2014 to $75^{\text {th }}$ in 2015 (Dutta, Geiger and Lanvin B 2015) adding to the digital divide to be bridged by an e-intervention.

Factors predicting older persons' technology acceptance and adoption (particularly mobile phones) were also identified by Renaud and van Biljon (2008) who found that, unlike this study, attitude is not a determinant. Renaud and van Biljon (2008) found that technology acceptance was strongly linked to an active adoption phase where emphasis was laid on appropriation, experimentation and exploration to enhance ease of use. This is often omitted when older persons receive hand-me-down mobile phones, which can result in failure to perceive the mobile phone as easy to use (Senior Technology Acceptance and Adoption Model) (Renaud and van Biljon, 2008). Older persons are seen not to 
select mobile phones for the novelty that they offer, but for the perceived ease of use (Conci et al., 2009).

This study found no significant differences between gender and Perceived Usefulness and Perceived Ease of Use. This is contrary to the findings by Koivisto and Hamari, (2014) where ease of use was negatively influenced by gender, and of Chen and Chan (2014) showing men to be more likely to use technology. Further showing variance with regards to gender and ease of use, women may be more subject to social influence which may affect their perceptions (Venkatesh, Morris and Ackerman, 2000). This factor may explain the time in residence variable that had a significant influence on Perceived Ease of Use. Children and other relatives have been shown to have a strong influence on Perceived Usefulness (Conci et al., 2009).

In terms of which technology-assisted communication had the greatest appeal to the participants; video chat appealed more to the younger participants and emailing more to the older participants. In planning any intervention with technology-assisted communication, it could be easier to overcome technology anxiety and low perceived ease of use, if social support in the form of a peer leader is identified as a resource person and available throughout the programme (Heinz et al., 2013; Lee and Coughlin 2015). Further it would be preferable when introducing technology-assisted communication for the older persons that this is done gradually one device at a time (van Biljon and Renaud, 2008). The present study suggests that video chat ought to be introduced first, countering the effects of computer anxiety (Renaud and van Biljon, 2008). However, consideration needs to be given to factors influencing future use linked to the person, the technology and the support processes in place for residents. Personal factors such as changes in visual acuity that ageing brings may require larger screen images and centrally placed icons on a sharp contrast (Renaud and Van Biljon, 2008). In addition, technological factors such as the network capacity in countries with low bandwidth should also be considered (Dutta et al., 2015) to prevent frustration for the users.

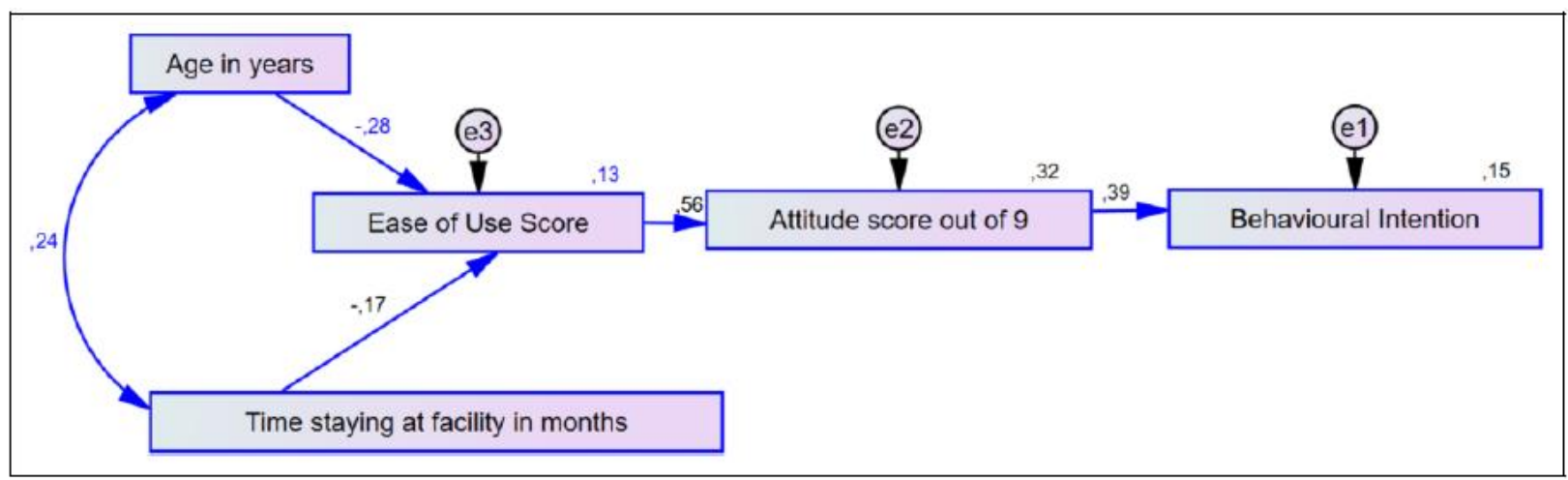

Figure 2. Technology Acceptance Model.

As the direct care staff may play a key role in providing technological support to residents, the levels of communication technology literacy of direct care staff and low levels of trust 
between nurses and residents (Chipps and Jarvis, 2015) should be addressed to ensure adequate support processes for residents. Any further investigation would seek to identify the best ways of training the direct-care staff in the use of whatever device is first introduced, and also the best ways of imparting their acquired skills to residents, in the knowledge that special difficulties of adaptability and dexterity accompany the learning process among the elderly (Renaud and van Biljon, 2008).

\section{Limitations}

The authors acknowledge that despite testing for external influences in engaging with the TAM, utilizing the more expanded TAM II might have allowed for more direct testing of the facilitating conditions. A question on how devices were obtained would have been illuminating, as some participants may have been using hand-me-down devices without a process of familiarization. This may have negatively influenced perceptions about technology-assisted communication devices (Renaud and van Biljon, 2008). Furthermore, it has been suggested that actual observation of an older person's use of a mobile phone is preferable to a self-report questionnaire (Renaud and van Biljon, 2008). The number of respondents was low for inferential analysis and structural modelling, though adequate for regression analysis, and it is recommended that this analysis is repeated with bigger samples in a future study. Lastly, the constructs in the TAM predicted behavioural intention, but not one single construct alone.

\section{Conclusion and Recommendations}

Technology has a significant part in enhancing support networks. It holds particular relevance in resource restricted settings as it is a form of social intervention that does not call upon the high-level professional skills of mental-health-care practitioners (Tomlinson et al., 2009).

Consideration needs to be given to older persons' technological readiness prior to the introduction of technology-assisted communication. Technology-assisted communication, adapted with forethought and sensitivity to the special requirements of the elderly, is a tool with the potential to expand and enrich their social networks and, in consequence, enhance their mental health. It is also suggested that future studies utilize the Senior Technology Acceptance and Adoption Model which recognizes the adoption process by older persons (Renaud and van Biljon, 2008). 


\section{References}

Chipps J and Jarvis MA (2015) Social capital and mental well-being of older people residing in a residential care facility in Durban, South Africa. Aging \& Mental Health 1-7.

Chen K and Chan AHS (2014) Gerontechnology acceptance by elderly Hong Kong Chinese: a senior technology acceptance model (STAM). Ergonomics 57(5), 635-652

Cornwell EY and Waite LJ (2009) Social disconnectedness, perceived isolation, and health among older adults. Journal of Health and Social Behavior 5o(1): 31-48.

Cotton SR, Anderson WA and McCullough BM (2013) Impact of Internet use on loneliness and contact with others among older adults: cross-sectional analysis. Journal of Medical Internet Research 15(2):e39 doi:10.2196/jmir.2306

Conci M, Pianesi F and Zancanaro M (2009) Useful, social and enjoyable: Mobile phone adoption by older people. In Human-Computer Interaction-INTERACT 2009 (63-76). Springer Berlin Heidelberg.

Davis FD (1989) Perceived usefulness, perceived ease of use, and user acceptance of information technology. MIS Quarterly 13(3): 319-340.

Drageset J, Kirkevold M and Espehaug B (2011) Loneliness and social support among nursing home residents without cognitive impairment: a questionnaire survey. International Journal of Nursing Studies 48(5): 611-619.

Dutta S, Geiger T and Lanvin B (2015) The Global Information Technology Report 2015. In World Economic Forum. Retrieved from http://www3.weforum.org/ docs/WEF_GITR_InsideCover_2015.pdf. Accessed o8 April 2016.

Fokkema T and Knipscheer K (2007) Escape loneliness by going digital: A quantitative and qualitative evaluation of a Dutch experiment in using ECT to overcome loneliness among older adults. Aging and Mental Health 11(5): 496-504.

Gefen D, Straub DW and Boudreau M (2000) Structural equation modeling techniques and regression: guidelines for research practice. Communications of Association for Information Systems 4, Article 7. Retrieved from http://cits.tamiu.edu/kock/NedWebArticles/Gefene tal20oo.pdf. Accessed on 07 April 2016.

Golden J, Conroy RM, Bruce I, Denihan A, Greene E, Kirby M and Lawlor BA (2009) Loneliness, social support networks, mood and wellbeing in community-dwelling elderly. International Journal of Geriatric Psychiatry 24(7): 694-700.

Heinz M, Martin P, Margrett JA, Yearns M, Franke W, Yang H-I, Wong J and Chang CK (2013) Perceptions of technology among older adults. Journal of Gerontological Nursing 39(1):42.

Holden R.J and Karsh BT (2010) The technology acceptance model: its past and its future in health care. Journal of Biomedical Informatics 43(1):159-172.

Keating N, Swindle J and Foster D (2005) The role of social capital in aging well. Social Capital in Action: Thematic Policy Studies 24-51.

Koivisto $J$ and Hamari $J$ (2014) Demographic differences in perceived benefits from gamification. Computers in Human Behavior 35: 179-188.

Kwan A (2013) mHealth solutions for improving mental health and illness in the aging process. mHealth Alliance, UN Foundation. Retrieved from http://www. 
mhealthknowledge.org/sites/default/files/7_mHA-Aging-Paper3_o92713.pdf. Accessed on 07 April 2016.

Lee YS (2007) Older adults' user experiences with mobile phones: identification of user clusters and user requirements. PhD thesis Virginia Polytechnic Institute and State University.

Lee C and Coughlin JF (2015) PERSPECTIVE: older adults' adoption of technology: an integrated approach to identifying determinants and barriers. Journal of Product Innovation Management 32(5): 747-759.

Lu J, Yu C-S, Liu C and Yao JE (2003) Technology acceptance model for wireless Internet. Internet Research 13(3): 206-222.

Luppa M, Sikorski C, Luck T, Ehreke L, Konnopka A, Wiese B, Weyerer S, Kö nig HH and Riedel-Heller SG (2012) Age-and gender-specific prevalence of depression in latestlife-systematic review and meta-analysis. Journal of Affective Disorders 136(3):212221.

Nahm ES, Resnick B and Mills ME (2003) A model of computer-mediated social support among older adults. In AMIA Annual Symposium Proceedings (Vol. 2003, p. 948). American Medical Informatics Association.

Nayak LU, Priest L and White AP (2010) An application of the technology acceptance model to the level of Internet usage by older adults. Universal Access in the Information Society 9(4): 367-374.

Nyqvist F, Nyga rd M and Jakobsson G (2012) Social participation, interpersonal trust, and health: A study of 65- and 75-year-olds in western Finland. Scandinavian Journal of Public Health 40(5): 431-438.

Pillay U, Roberts B and Rule SP (2006) South African social attitudes: changing times, diverse voices. HSRC Press. Retrieved from www.hsrcpress. Accessed on o9 April 2016.

Renaud K and Van Biljon J (2008 October) Predicting technology acceptance and adoption by the elderly: a qualitative study. In Proceedings of the 2008 Annual Research Conference of the South African Institute of Computer Scientists and Information Technologists on IT Research in Developing Countries: Riding the Wave of Technology (pp. 210-219). ACM.

Solhaug HI, Romuld EB, Romild U and Stordal E (2012) Increased prevalence of depression in cohorts of the elderly: an 11-year follow-up in the general population-the HUNT study. International Psychogeriatrics 24(1): 151-158.

Statistics South Africa (2014) General Household Survey 2013. Pretoria. Retrieved from http://www.statssa.gov. za/publications/Po318/P03182013.pdf. Accessed on 24 January 2016.

Strudwick G (2015) Predicting nurses' use of healthcare technology using the technology acceptance model: an integrative review. Computers Informatics Nursing 33(5): 189-198.

Tiong WW, Yap P, Huat Koh GC, Phoon Fong N and Luo N (2013) Prevalence and risk factors of depression in the elderly nursing home residents in Singapore. Aging \& Mental Health 17(6): 724-731. 
Tomlinson M, Grimsrud AT, Stein DJ, Williams DR and Myer L (2009) The epidemiology of major depression in South Africa: results from the South African stress and health study. SAMJ: South African Medical Journal 99(5): 368-373.

Turner M, Kitchenham B, Brereton P, Charters S and Budgen D (2010) Does the technology acceptance model predict actual use? A systematic literature review. Information and Software Technology 52(5): 463-479.

Tsai HH, Tsai YF, Wang HH, Chang YC and Chu HH (2010) Videoconference program enhances social support, loneliness, and depressive status of elderly nursing home residents. Aging and Mental Health 14(8): 947-954.

van Groenou MB, Hoogendijk EO and van Tilburg TG (2013) Continued and new personal relationships in later life differential effects of health. Journal of Aging and Health 25(2): 274-295.

van Kemenade S, Roy J and Bouchard L (2006) Social networks and vulnerable populations: findings from the GSS. Health Policy Research Bulletin 12: 16-20.

Venkatesh V, Morris MG and Ackerman PL (2000) A longitudinal field investigation of gender differences in individual technology adoption decision-making processes. Organizational Behavior and Human Decision Processes 83(1): 33-60.

Wang H, Dwyer-Lindgren L, Lofgren KT, Rajaratnam JK, Marcus JR, Levin-Rector A, Levitz CE, Lopez AD and Murray CJ (2013) Age-specific and sex-specific mortality in 187 countries, 1970-2010: a systematic analysis for the Global Burden of Disease Study 2010. The Lancet 380(9859): 2071-2094.

White H, McConnell E, Clipp E, Branch LG, Sloane R, Pieper C and Box TL (2002) A randomized controlled trial of the psychosocial impact of providing internet training and access to older adults. Aging \& Mental Health 6(3): 213-221. 


\section{Appendix A: Technology Assisted Communication Questionnaire}

This section deals with the ease of use and usefulness of using communication devices.

How easy (confident) and how useful is it for you to use each of the devices and functions listed below. Please mark your choice with an $\mathrm{X}$.

\begin{tabular}{|c|c|c|c|c|c|c|c|c|c|c|}
\hline & \multicolumn{5}{|c|}{ I. Easy to use } & \multicolumn{5}{|c|}{ 2. Useful to use } \\
\hline & $\begin{array}{l}\text { Don't } \\
\text { use }\end{array}$ & $\begin{array}{c}\text { Very } \\
\text { difficult }\end{array}$ & Difficult & Easy & $\begin{array}{l}\text { Very } \\
\text { Easy }\end{array}$ & $\begin{array}{l}\text { Don't } \\
\text { use }\end{array}$ & $\begin{array}{l}\text { Not } \\
\text { useful } \\
\text { at all }\end{array}$ & $\begin{array}{c}\text { Somewhat } \\
\text { useful }\end{array}$ & Useful & $\begin{array}{l}\text { Very } \\
\text { Useful }\end{array}$ \\
\hline $\begin{array}{l}\text { a. Cellphone to make calls } \\
\text { b. Cellphone to receive calls } \\
\text { c. Cellphone to send SMS } \\
\text { d. Cellphone to receive SMS } \\
\text { e. Cellphone for instant messaging } \\
\quad \text { (e.g. BBM }{ }^{\mathbb{R}} \text { or WhatsApp) } \\
\text { f. Cellphone to video chat (Skype TM } \text { ) } \\
\text { g. Cellphone to receive or send an } \\
\text { e-mail } \\
\text { h. Cellphone for social media e.g. } \\
\text { Facebook } \\
\text { i. Cellphone for internet } \\
\text { j. Cellphone for playing games } \\
\text { k. Computer to receive e-mails } \\
\text { I. Computer to send e-mails }\end{array}$ & & & & & & & & & & \\
\hline
\end{tabular}

(continued) 


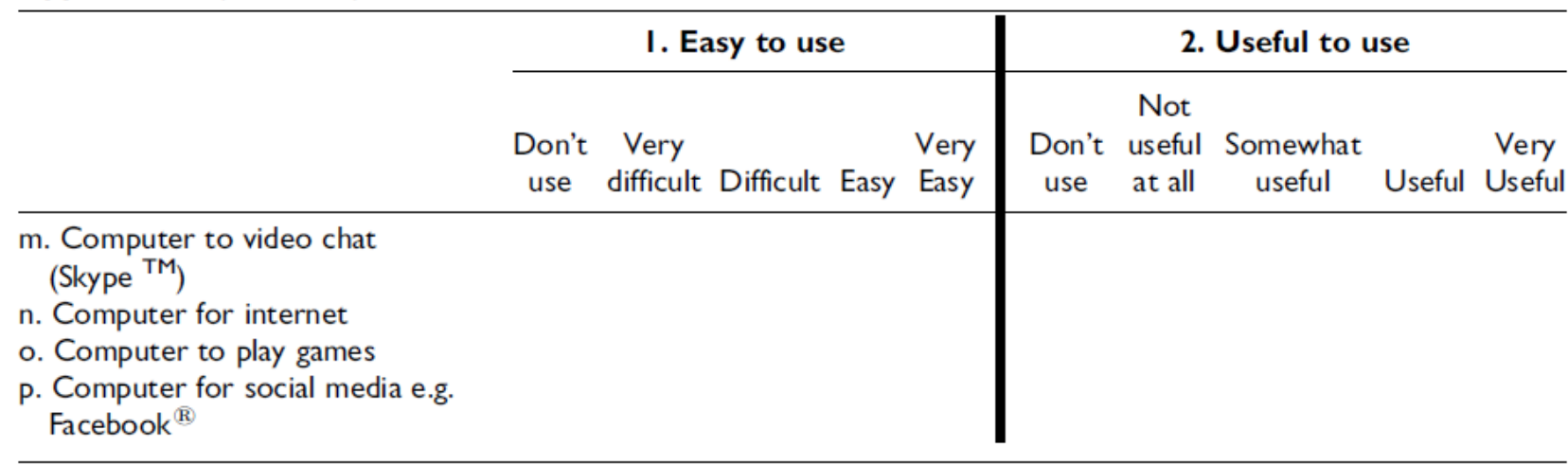

This next set of questions has statements about technologically assisted communication to which you need to choose "yes" or" no." Examples of technologically assisted communication are SMS, instant messaging (e.g. BBM ${ }^{\circledR}$, WhatsApp), email, video chat $\left(S k y p e^{T M}\right)$ or social media (e.g. Facebook $\left.{ }^{\circledR}\right)$

\section{Perceived usefulness of technologically assisted communication}

\begin{tabular}{|c|c|c|}
\hline $\begin{array}{l}\text { a. Apart from phone calls, I would be able to contact my family /friends using other technology } \\
\text { assisted devices ...... }\end{array}$ & Yes & No \\
\hline $\begin{array}{l}\text { b. I could improve my contact with my family/friend/s by me using technology assisted } \\
\text { devices } \ldots \ldots \ldots \ldots \ldots \ldots \ldots \ldots \ldots \ldots \ldots \ldots \ldots \ldots \ldots \ldots \ldots \ldots \ldots \ldots \ldots \ldots \ldots \ldots \ldots \ldots \ldots\end{array}$ & Yes & No \\
\hline $\begin{array}{l}\text { c. I could have greater control over my contact with my family / friend/s by me using technology } \\
\text { assisted devices. } \ldots \ldots \ldots \ldots \ldots \ldots \ldots \ldots \ldots \ldots \ldots \ldots \ldots \ldots \ldots \ldots \ldots \ldots \ldots \ldots\end{array}$ & Yes & No \\
\hline
\end{tabular}

\section{Behavioral intention towards technologically assisted communication}

\begin{tabular}{lr}
\hline a. I am already using technologically assisted communication devices $\ldots \ldots \ldots \ldots \ldots \ldots \ldots \ldots \ldots \ldots \ldots \ldots$ & No \\
b. I intend to use technology assisted devices in the future $\ldots \ldots \ldots \ldots \ldots \ldots$ & No \\
c. I have confidence that I will be able to use technology assisted devices $\ldots \ldots \ldots$ & Yes \\
d. People who are important to me think I should use technology assisted devices & Yes \\
\hline
\end{tabular}

\section{Attitude towards technologically assisted communication}

\begin{tabular}{|c|c|}
\hline a. It is easy for me to learn something new such as using a new cellphone $\ldots \ldots \ldots$ & Yes \\
\hline b. I have a positive attitude towards using technology assisted devices $\ldots \ldots \ldots \ldots \ldots$ & Yes \\
\hline c. I like the idea of being able to contact my family / friend/s using technology assisted devices & Yes \\
\hline 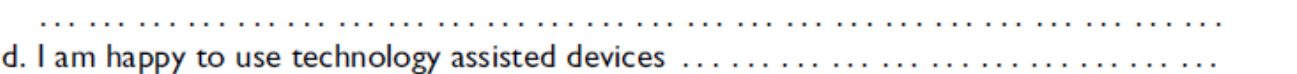 & Yes \\
\hline
\end{tabular}

\section{Ranking of appeal of different types of technologically assisted communication.}

Rank which technologically assisted communication generally has the greatest appeal to you (Please mark with a 5 in the box next to your choice) to which technologically assisted communication generally has the least appeal to you (Please mark with a 1 in the box next to your choice). 

a. E-mail
b. Instant Messaging ( $\mathrm{BBM}_{\mathbb{R}} /$ WhatsApp)
c. SMS
d. Social media (e.g. facebook $_{\overparen{R}}$ )
e. Video chat (Skype ${ }^{\text {TM }}$ ) 